\title{
Intelligent Safety Transport Framework for Schools: A Review of Route Planning and Tracking Systems
}

\author{
Manoharan Ramachandran, Reza Sahandi, Simant Prakoonwit and Wajid Khan \\ Creative Technology Department, Faculty of Science and Technology, Bournemouth University, Bournemouth, United Kingdom
}

\begin{abstract}
This work presents a review of recent literature in intelligent school transportation frameworks, particularly focusing on route planning, real time vehicle and children tracking. The focus on route planning and tracking is to identify the hidden practical problems and threats present in school transportation, bearing in mind safety. Different methods and technologies used for route planning and vehicle as well as children tracking are reviewed. A discussion is provided on the current frameworks along with the challenges and future research direction.
\end{abstract}

\section{Introduction}

School Transportation System (STS) is safety critical which involves school children (students) who are the most vulnerable users of roads [1]. Recent events and accidents highlighted the need for improving the existing school transportation and bus monitoring systems [52], [53]. Statistics demonstrate that in England alone 85,814 children were wounded near the schools during the period 2007 to 2013, which is equivalent to 1,190 a month [2], [3]. Moreover, during the period 2006 to 2011 there were 557,200 vehicle collisions around schools [2], [3]. As a result, proper safety route planning and monitoring strategies for school vehicles and children are in high demand [4], [5]. Efforts to reduce school transport injuries have begun through constraint-based school bus routing [12] and peer to peer children monitoring [13] while they are on route. Recent innovations [6]-[8] in STS, gave birth to Intelligent School Transportation Systems (ISTSs), which addressed some of the issues [9], [10], [11] in STS such as optimal routing of school vehicles, continuous monitoring of school buses and children. An ISTS incorporates the innovation and adoption of recent technologies to create applications for the benefit of school transportation. Major technologies involved in ISTS are school bus route planning systems, school vehicle-children tracking and monitoring systems. School bus route planning systems rely on the history of School Bus Routing Problems (SBRPSs) which have been studied since the first published work by Newton and Thomas in 1969 [14]. There are only limited publications available for reviewing school bus routing problems [15]-[17]. Junhyuk and Byung-in Kim [17] describe school bus routing problems for a fleet of school buses as an efficient schedule planning, where children are picked up by each bus from various geographical locations and delivered to their respective schools, while satisfying a set of constraints. The main reasons behind the school bus routing problems were frequent changes in the number of children per stop, rerouting during temporary roadworks and traffic jams. According to Desrosiers et al. [15], there are five steps to reduce school bus routing problems, namely, data preparation, bus stop selection, bus route generation, school bell time adjustment and route scheduling. Parents spend more time on the streets and making phone calls while waiting for school buses due to the unpredictable nature of the traffic, particularly during the winter months. For this very reason, vehicle-children tracking systems were made. School vehicle-children tracking is a process of tracking the school bus and children inside it using tracking devices such as the Global Positioning System (GPS) [38] and Radio Frequency Identification (RFID) systems tags [39], which are commonly used in tracking technologies. The tracked data may be utilized by the school transportation department and shared with parents to let them recognize the location of their children. Most of the published work so far on ISTS have focused on route planning systems and only limited work has been done to address the whole school transport system [18], [19]. In this paper, a review of recent studies in intelligent safety school transportation systems with a focus on route planning and tracking is presented. A fresh perspective and functions for an ISTS framework are provided along with the challenges and further research direction.

\section{Intelligent school transportation systems}

It was indicated earlier that ISTSs attempt to provide safe and secure transportation for school children through design, development and integration using appropriate technologies. However, limited works have been done so 
far in addressing this for school transportation and child safety. A recent Europe funded project conducted in Sweden "SAFEWAYTOSCHOOL" provided a holistic and safety framework for children [1], [11], [18], [19], [38]. This project addresses most of the difficulties faced during school transportation through a door to door approach (between home and school). Figure 1 shows a holistic approach to this project. At first, safest routes are considered for children to reach the bus stop. When a child reaches the bus stop, an alert light is automatically turned on at the bus stop. When the bus reaches the bus stop to pick up the child, a warning sign in the bus is turned on. During the journey towards the school, the children are notified to put the seat belts on. Also, audiovisual information is provided about the destination before reaching the school. Once the bus reaches the school stop, a warning notification light is turned on in the bus and the bus stop is also turned on. Finally, on arrival at the school, a notification message is sent to parents.

Atsushi et al., proposed a safety support system through ad-hoc network formed using mobile phones to increase the safety of children when walking between bus stops and home [44]. Volunteers who maintain safety in the local community assist the children when walking between home and bus stop. Both the volunteers and children are provided with mobile phones which facilitate the Bluetooth function. A safety support mobile application is installed on these mobile phones. Bluetooth poles are placed at even distance intervals between the home and bus stop. When children's and volunteer's mobile phones come into contact with these poles, the mobile application automatically connect them. The volunteer's mobile application obtains information about the exact location of the child and shares it with the parents and caretakers. A warning message is sent to parents and volunteers if any abnormalities like deviating from the normal path are found.

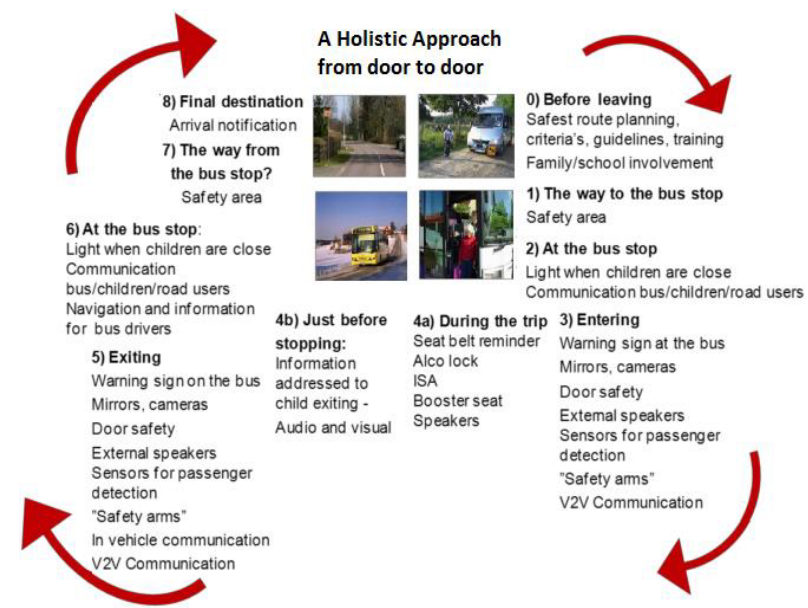

Figure 1. Holistic approach of school transportation [18].

\section{Functions of ISTSs}

School transportation systems have been evolving in the past decades. ISTSs were developed due to recent advancements in route planning systems [6], [12], [23], [29]-[33], [35]-[37], school vehicle-student tracking and monitoring systems [8], [18], [38]-[43]. Figure 2 shows the functions of a typical ISTS. Each ISTS function applies its own methods to find the best solutions [6], [7], [8], [12], [17], [21] for the challenges in each function. For instance, GPS [39] and RFID [18] tags are used for vehicle and student tracking. However, providing an accurate and a non-intrusive service at all time is challenging [7].

\begin{tabular}{lll} 
& \multicolumn{2}{c}{ Intelligent School Transportation System } \\
Route Planning & \multicolumn{1}{c}{ Vehicle Tracking } & Student Tracking \\
- Data Preparation & - Location Tracking & - Location Tracking \\
- Bus Stop Selection & - Behaviour Monitoring & - Health Monitoring \\
- Route Generation & & \\
- School Bell Time Adjustment & \\
- Route Scheduling &
\end{tabular}

Figure 2. Functions of a typical intelligent school transportation system.

\subsection{Route planning systems}

In schools, manual route planning is an intensive task and it consumes a considerable amount of time for selecting appropriate safety routes, as well as the number of busses required for a route. Typically, school transportation departments perform manual route planning at the beginning of each term due to the changes in the number of students using the service. To make this process more efficient, automated route planning systems are used. To avoid school bus routing problems, automated route planning systems utilize the following five steps sequentially: preparation of data, selection of bus stops, generation of school bus routes, adjustment of school bell time and scheduling of school bus routes [15].

\subsubsection{Data Preparation (DP)}

Data for the next four sub problems (Bus Stop Selection (BSS), Bus Route Generation (BRG), School Bell Time Adjustment (SBTA) and Route Scheduling (RS) of school bus routing problem are created through data preparation. In this step, a dataset containing a single road network with student residence coordinates, the school constraints (start-end time of schools, maximum ride time, etc.), number of vehicles with seating plan and an Origin-Destination (OD) matrix are created. In an OD matrix, the shortest distance between the school location, student locations and the bus origin location are stored. Various shortest path algorithms and a geographic information system (GIS) are applied to calculate the OD matrix [17]. Performances of the shortest path algorithms are compared by Kim and Jeong and an approximation approach for the OD matrix generation is developed [20]. Thus, the dataset (students, schools, vehicles and OD matrix) created in the data preparation is used to prevent school bus routing problems.

\subsubsection{Bus Stop Selection (BSS)}

It is the process of selecting a number of school bus stops and assigning students to them. Bus stop selection can be 
done through heuristic approaches [29], [36], [37] or by exact methods based on mathematical programming [12], [21], [22], [23], [37]. The heuristic approach follows either the Location-Allocation-Routing (LAR) [15], [24], [25], [26] or the Allocation-Routing-Location (ARL) [27], [28], [29] strategies. In LAR strategy, a set of bus stops for a school are selected first and the students are allocated to these bus stops based on the distance between the bus stop and their home. Once the children are assigned to these bus stops, the routes are generated. LAR strategy tends to create more routes since bus stop selection and children assignments are done before the route generation. ARL strategy overcomes the drawback of LAR by performing it in the opposite order. At first, children are grouped into clusters with respect to vehicle capacity constraints. Subsequently, bus stops are selected and routes between each cluster are generated. Finally, the clusters are assigned to the bus stop by satisfying constraints such as maximum walking distance between home and bus stop, maximum number of children for a bus stop and minimum distance between each bus stop [17].

\subsubsection{Bus Route Generation (BRG)}

School bus routes are generated by analysing the data gathered from the previous two processes. The route generation algorithms classified into either "routecluster" or "cluster-route" approaches [24]. In the "routecluster" approach, all the stops in a large route are built using the traveling salesman algorithm from which small routes are partitioned based on the constraints [14], [24]. In the "cluster-route" approach, students are grouped into clusters and each cluster is served as a route satisfying the constraints [25], [27], [28]. The constraints that are categorized to minimise school bus routing problem are represented in Table 1. They are, Vehicle Capacity (VC) - number of children allowed for a vehicle, maximum Ride Time (RT) - travel time of each child, school Time Window (TW) - arrival time of vehicle at school, maximum Walking Distance (WD) - distance between student home and bus stop, minimum number of Students for a Route (SR), Passenger Demand (PD) - route request by student during travel, maximum Bus stops Visited (BV), maximum Waiting Time (WT) - allowed waiting time for student at the bus stop and Terrain Type (TT) type of road selected.

\subsubsection{School Bell Time Adjustment (SBTA)}

It has performed for schools where the start and end times are not considered as constraints but as decision variables.
This is to identify the optimal start and end time to reduce the number of buses used [17].

\subsubsection{Route Scheduling (RS)}

The start and end times for each route are scheduled through route scheduling using a series of routes that can be visited successfully by the same bus. SBTA and RS are implemented when buses transport students from more than one school.

Minimisation of school bus routing problems is performed based on the nature of the underlying problem characteristics as follows; the number of schools: single (vehicle serves only one school) [35] or multiple (vehicle serves more than one school) [37]; fleet type: homogeneous (vehicles seating capacity remains the same) [23] or heterogeneous (vehicles seating capacity varies) [37]; service type: rural [31] or urban [30]; [17]. Table I also represents a comparison of methods applied by various researchers since 2010 for reducing school bus routing problems. For the work done before 2010, Park and Kim in [17] provide a comprehensive review of school bus routing problem.

\subsection{School vehicle tracking and monitoring systems}

School vehicle tracking is similar to common vehicle tracking which involves the use of GPS devices to track the vehicle. A GPS device in the school vehicle automatically provides updates of its location coordinates to a cloud server, which process and plots these coordinates on a virtual map. This map can be accessed by the stakeholders (transport department and parents) for information about the location of the school vehicle. School vehicle tracking systems can be utilized for two purposes: location tracking and vehicle behaviour monitoring

\subsubsection{Vehicle Location Tracking (VLT)}

The most commonly applied technology for position tracking systems is GPS. Grounded along the tracking nature, location tracking can be classified as real-time tracking [39] and lag-time tracking [38]. In real-time tracking, the location sensor in the vehicle (GPS) frequently updates a server in the real-time [39], [40]. In lag-time tracking, an active RFID unit in the vehicle communicates with the bus stop when it reaches near it and through that the vehicle is tracked [38].

Table 1. Representation of recent works in school bus routing problem (2010-2016).

\begin{tabular}{|l|l|l|l|l|}
\hline \multicolumn{1}{|c|}{ Study } & $\begin{array}{c}\text { Considered } \\
\text { school bus } \\
\text { routing } \\
\text { problem sub } \\
\text { Problems }\end{array}$ & Constraints & Method & Goal \\
\hline $\begin{array}{l}\text { Jalel Euchi et } \\
\text { al., 2012 [30] }\end{array}$ & BSS,BRG,RS & VC,RT,PD & $\begin{array}{l}\text { Artificial ant colony with variable } \\
\text { neighborhood local search } \\
\text { algorithm }\end{array}$ & $\begin{array}{l}\text { Minimizing the total number of } \\
\text { buses required }\end{array}$ \\
\hline
\end{tabular}




\begin{tabular}{|c|c|c|c|c|}
\hline $\begin{array}{l}\text { Riera et al., } \\
2012 \text { [23] }\end{array}$ & BSS,RG & $\mathrm{VC}, \mathrm{WD}$ & $\begin{array}{l}\text { Branch and cut approach based } \\
\text { Exact algorithm }\end{array}$ & $\begin{array}{l}\text { Number of routes and route length } \\
\text { minimization }\end{array}$ \\
\hline $\begin{array}{l}\text { Pacheco et al., } \\
2012 \text { [31] }\end{array}$ & RG,RS & RT & $\begin{array}{l}\text { Multi-objective adaptive memory } \\
\text { programming }\end{array}$ & $\begin{array}{l}\text { Minimizing the duration of the } \\
\text { longest routes and total distance } \\
\text { traveled }\end{array}$ \\
\hline $\begin{array}{l}\text { Byung In et } \\
\text { al., 2012 [32] }\end{array}$ & $\mathrm{RS}$ & TW & $\begin{array}{l}\text { Branch and bound approach based } \\
\text { on assignment problem }\end{array}$ & $\begin{array}{l}\text { Optimization of bus schedules to } \\
\text { serve all the given trips within the } \\
\text { given TW }\end{array}$ \\
\hline $\begin{array}{l}\text { Junhyuk et al., } \\
\text { 2012[33] }\end{array}$ & RG,RS & VC,RT,TW & Mixed load improvement algorithm & $\begin{array}{l}\text { Minimizing the total number of } \\
\text { buses required }\end{array}$ \\
\hline $\begin{array}{l}\text { Patrick et al., } \\
2013 \text { [29] }\end{array}$ & BSS,RG & $\begin{array}{l}\text { VC,TW,SR,W } \\
\text { D }\end{array}$ & $\begin{array}{l}\text { GRASP+VND metaheuristic } \\
\text { approach }\end{array}$ & $\begin{array}{l}\text { To integrate BSS and RG through } \\
\text { meta-heuristic approach with } \\
\text { simplified implementation }\end{array}$ \\
\hline $\begin{array}{l}\text { Riera et al., } \\
2013[12]\end{array}$ & $\mathrm{BSS}, \mathrm{RG}$ & $\begin{array}{l}\text { VC,RT,SR,B } \\
\text { V,WD }\end{array}$ & $\begin{array}{l}\text { Set partitioning formulation based } \\
\text { branch and price algorithm }\end{array}$ & $\begin{array}{l}\text { Minimizing the number of routes, } \\
\text { route length and walking distance }\end{array}$ \\
\hline $\begin{array}{l}\text { Kinable et al., } \\
2014[35]\end{array}$ & $\mathrm{BSS}, \mathrm{RG}$ & VC,SR,RT & Exact branch and price framework & Minimizing the routing costs \\
\hline $\begin{array}{l}\text { Michael Bogl } \\
\text { al., } 2015 \text { [36] }\end{array}$ & $\mathrm{BSS}, \mathrm{RG}, \mathrm{RS}$ & VC,WD,WT & $\begin{array}{l}\text { Heuristic solution } \\
\text { allowing transfers }\end{array}$ & Minimizing the operational costs \\
\hline $\begin{array}{l}\text { Xiaopan et al., } \\
2015 \text { [37] }\end{array}$ & RG,RS & TW,RT & $\begin{array}{l}\text { Exact mixed integer programming } \\
\text { and two-stage metaheuristic method }\end{array}$ & $\begin{array}{l}\text { Minimizing the number of routes } \\
\text { and total number of buses }\end{array}$ \\
\hline $\begin{array}{l}\text { Cristiano et } \\
\text { al., } 2015 \text { [6] }\end{array}$ & RG,RS & $\begin{array}{l}\text { VC,TT,SR,W } \\
\text { D }\end{array}$ & Mixed load approach & $\begin{array}{l}\text { Minimizing the total traveled } \\
\text { distance of a heterogeneous fleet }\end{array}$ \\
\hline
\end{tabular}

Table 2. Representation of various research in school vehicle tracking and monitoring.

\begin{tabular}{|l|l|l|l|l|}
\hline \multicolumn{1}{|c|}{ Study } & Sensor type & $\begin{array}{c}\text { Type of } \\
\text { tracking } \\
\text { considered }\end{array}$ & \multicolumn{1}{|c|}{$\begin{array}{c}\text { Nature of } \\
\text { tracking }\end{array}$} & Goal \\
\hline Anund et al., 2011 [38] & $\begin{array}{l}\text { Active } \\
\text { RFID }\end{array}$ & VLT & Lag time & $\begin{array}{l}\text { To monitor bus location and providing bus } \\
\text { time information to parents }\end{array}$ \\
\hline Khaled et al., 2013 [39] & GPS & VLT & Real time & $\begin{array}{l}\text { To smartly track the school bus and share the } \\
\text { location info with parents }\end{array}$ \\
\hline Zambada et al., 2015 [40] & $\begin{array}{l}\text { GPS,acceler } \\
\text { ometer }\end{array}$ & VLT, VDBM & Real time & $\begin{array}{l}\text { Increasing the safety of school bus monitoring } \\
\text { through InterneT of things (IoT) }\end{array}$ \\
\hline
\end{tabular}

Table 3. Representation of various research in school student tracking and monitoring.

\begin{tabular}{|l|l|l|l|l|}
\hline \multicolumn{1}{|c|}{ Study } & $\begin{array}{c}\text { Sensor/Technology } \\
\text { used }\end{array}$ & $\begin{array}{c}\text { Type of } \\
\text { tracking } \\
\text { considered }\end{array}$ & \multicolumn{1}{|c|}{$\begin{array}{c}\text { Nature of } \\
\text { tracking }\end{array}$} & Goal \\
\hline Anund et al., 2010 [18] & RFID & SLT, IVA & Active & $\begin{array}{l}\text { To track and monitor the school } \\
\text { students inside the school bus }\end{array}$ \\
\hline Saranya et al., 2012 [41] & GPS & SLT & Active & $\begin{array}{l}\text { To track the location and emotional } \\
\text { status of the student }\end{array}$ \\
\hline Khaled et al., 2013 [39] & RFID & SLT & Passive & $\begin{array}{l}\text { To track and monitor the student } \\
\text { during their trip to and from school on } \\
\text { school bus }\end{array}$ \\
\hline Huang et al., 2014 [8] & GPS/Bluetooth & SLT & Active & $\begin{array}{l}\text { To develop a mobile based child } \\
\text { security monitoring system in school } \\
\text { travel }\end{array}$ \\
\hline Anwaar et al., 2015 [42] & RFID & SLT, IVA & Passive & $\begin{array}{l}\text { To track the student location and } \\
\text { monitoring bus boarding times }\end{array}$ \\
\hline Peter et al., 2015 [43] & GPS/Heart rate & SLT, HM & Passive & $\begin{array}{l}\text { To monitor the student physical } \\
\text { activities from school to home travel }\end{array}$ \\
\hline
\end{tabular}

\subsubsection{Vehicle-Driver Behaviour Monitoring (VDBM)}

It is used to detect the vehicle and driver behaviour to find the vehicle Estimated Time of Arrival (ETA) and rash driving. This is accomplished through various speed sensors on the vehicle like accelerometer along with GPS [40]. Table II shows characteristics of school vehicle tracking and monitoring systems. The main focus in the table is the different types of vehicle tracking systems used in ISTS.

\subsection{Student tracking and monitoring systems}

Similar to bus tracking, student tracking also employs similar technologies which are used to traverse the accurate placement of students. RFID is commonly employed for student tracking [42]. The student tracking system can be classified into two types: location tracking and health monitoring. 


\subsubsection{Student Location Tracking (SLT)}

The most common technique used for student location tracking is the utilization of RFID tags. RFID tags can show the nature of tracking. There are two types: active and passive RFID [39]. An active RFID tag has its own power source. Passive RFID have a chip embedded, which withdraws power from the RFID scanner that emits electromagnetic waves. Students are also tracked using GPS embedded devices [8], [41] which share their location with all the stakeholders (i.e) school authority, bus drivers and parents. In-Vehicle Attendance (IVA) is part of the student tracking system in which the presence of students is determined through RFID tags. The school bus with a RFID reader is used to read student' tag [42]. When a student enters the vehicle, it is automatically recorded and it is considered as active registration. If a student manually registers, it is considered as passive registration.

\subsubsection{Health Monitoring (HM)}

Health is an important factor for student monitoring. It not only helps the parents to understand their children's attentiveness but also helpful during emergencies. Health monitoring is performed through a heart rate sensor which is worn by the student [43]. Table III represents the characteristics of school student tracking and monitoring systems. The table shows different types of student tracking systems used in ISTS.

\section{ISTS challenges}

The implementation of various technologies (route planners, trackers, monitors) in the school transportation systems comes with many challenges which have to be resolved for the welfare of school children. A real-time school bus routing system has to be efficient and safe enough to transport the children. But considering all the safety aspects, selecting the school bus route is a challenging task. The routing problems get more complex when the nature of the problem changes (e.g. single school to multiple schools). Moreover, the safety aspects considered have to be easy to embed into the existing routing system without compromising performance. For an example, in [45] the energy consumption of vehicles is considered as one of the constraint for the route and it is directly added to the routing software without reducing the performance of the existing system. Dynamic traffic navigation (re-routing) will be of progressive importance in future years [46]. Implementing an efficient and dynamic traffic safety routing in urban school transportation is a challenging task. Tracking the school vehicle in real-time without the GPS network lag is important. The vehicle tracker lets the parents and children to comfortably plan their journey to the bus stop. A recent study on improving GPS-based vehicle positioning [47] stated that the GPS technology based conventional localization techniques are not able to provide reliable and accurate positioning in all situations. Also, providing real-time access to the stakeholders without network latency is a challenging task. Smartphone based vehicle-driver monitoring [50], [51] may improve the existing school bus tracking system because of the embedded sensors they use and the easy implementation. However, customizing it for school bus transportation by considering all safety characteristics will be challenging. Many student tracking systems have been developed in which mostly employ radio frequency based devices. Recent studies in radiation exposure [48], [49] reported that children are more likely to be vulnerable than healthy adults to radio frequency electromagnetic radiation. So the development of children tracking system with less or no radiation based methods will reduce the risk of a child's vulnerability towards radiations which is challenging.

\section{Conclusion and future directions}

Millions of people use school transportation in their daily lives. Children are seen as vulnerable users of the road and there is demand for safe school transportation organizations. Several technologies have been evolved to increase safety and to avoid fatal injuries to children to and from school. This paper presented a review of major technologies and approaches used in school transportation, including route planning systems, vehicle - student monitoring and tracking systems. Each category is reviewed and a comparison was made between different systems.

The existing systems suffer from many limitations. Safety levels of the existing systems can be improved in several ways. Proper safety frameworks are required to avoid unexpected and fatal child injuries. The comparison made between routing problems in this study reveals that, most of the existing literatures focus on the economy and the shortest routes to carry students, but they do not regard the safety aspects of the routes as precedence. Identification of vulnerable routes and safety of the routes should be considered in future systems. GPS is commonly utilized in most of the school bus tracking systems. Tracking the school bus in real-time without network latency is important. Improvement in GPS accuracy and reduction in network latency can enhance the efficiency and reduce safety risks in school transportation. Tracking the driving behaviour of school bus drivers can help transportation departments to take the necessary action, thereby enhancing the quality of transportation.

Development of radiation free devices for school children tracking systems will reduce children expose to radiation. We aim to propose a framework for safe route planning and tracking of school transportation with improved safety and a reduced risk of accidents.

\section{References}

1. Kostas Kalogirou, Eleni Chalkia, Evangelos Bekiaris and Frederik Diederichs, "An application for the information of children according their school transportation", in procedia - Social and behavioral sciences, Elsevier, (2012), pp. 363-372 
2. UK Road safety data, https://data.gov.uk/dataset/road-accidents-safety-data, Accessed on (Dec. 2015)

3. Angela Harrison, "Road safety: Insurers show accidents near schools", BBC news, (Aug. 2013)

4. Vasumita s adarsh, ET bureau, "Startups like Ospox and North star offer safety solutions for school kids parents", Economic times of India, (Aug. 29, 2014)

5. Teresa Yuan, "New GPS tracking devices on Kent school buses", King 5 News, (Jan. 4, 2016)

6. C. M. Silva, J. F. M. Sarubbi, D. F. Silva, M. F. Porto, and N. T. R. Nunes, "A Mixed Load Solution for the Rural School Bus Routing Problem," IEEE 18th International Conference on Intelligent transportation systems, pp. 1940-1945, (2015)

7. Faraj, M. F., Sarubbi, M., Silva, C. M., Porto, M. F., Tadeu, N., \& Nunes, R, "A Real Geographical Application for the School Bus Routing Problem". IEEE 17th International Conference on Intelligent Transportation Systems, Qingdao, China, (2014), pp. 2762-2767

8. Huang, Z., Gao, Z., Lu, H., Zhang, J., Feng, Z., \& Xia, H. "A Mobile Safety Monitoring System for Children". $10^{\text {th }}$ IEEE International Conference on Mobile Ad-Hoc and Sensor Networks, (2014), pp. 323-328.

9. Mammen, G., Stone, M. R., Buliung, R., \& Faulkner, $\mathrm{G}$, "Putting school travel on the map: Facilitators and barriers to implementing school travel planning in Canada". Journal of Transport \& Health, (2015), pp. 318-326

10. Harrison, F., Burgoine, T., Corder, K., van Sluijs, E. M. F., \& Jones, A, "How well do modelled routes to school record the environments children are exposed to?: A cross-sectional comparison of GIS-modelled and GPS-measured routes to school", International Journal of Health Geographics, (2014)

11. Falkmer, T., Horlin, C., Dahlman, J., Dukic, T., Barnett, T., \& Anund, A, Usability of the SAFEWAY2SCHOOL system in children with cognitive disabilities", European Transport Research Review, pp. 127-137, (2014)

12. Riera-Ledesma, J., \& Salazar-González, J. J., “A column generation approach for a school bus routing problem with resource constraints". Computers and Operations Research, pp. 566-583, (2013)

13. Yang, S.-H., \& Hsiung, P.-A, "Innovative Application of RFID Systems to Special Education Schools", IEEE Fifth International Conference on Networking, Architecture, and Storage, pp. 299-304, (2010)

14. Rita M. Newton, Warren H. Thomas," Design of school bus routes by computer", Socio-Economic Planning Sciences, Elsevier, pp. 75-85, (1969)

15. Desrosiers, J., Ferland, J.A., Rousseau, J.-M., Lapalme, G., Chapleau, L., "An overview of a school busing system", Scientific Management of Transport Systems, pp. 235-243, (1981)

16. Braca, J., Bramel, J., Posner, B., Simchi-Levi, D., "A computerized approach to the New York City school bus routing problem", IIE Transactions, pp. 693-702, (1997)
17. Junhyuk Park, Byung-In Kim, "The school bus routing problem: A review", European Journal of Operational Research, Elsevier, pp. 311-319, (2010)

18. Anund, A., Dukic, T., Börsbo, B., \& Falkmer, T., "Piloting smart safe school bus: exploration of security gains from implementation of a driver support system, additional technical equipment and intelligent bus stops", European Transport Research Review, pp. 157-163, (2010)

19. Anund, A., Dukic, T., Thornthwaite, S., \& Falkmer, T., "Is European school transport safe?-The need for a "door-to-door" perspective", European Transport Research Review, pp. 75-83, (2011)

20. Byung-In Kim and Sangwon Jeong, "A comparison of algorithms for origin-destination matrix generation on real road networks and an approximation approach," Computers and Industrial Engineering, vol. 56, no. 1, pp. 70-76, (2009)

21. Riera-Ledesma J, Salazar-Gonza'lez JJ., "Solving a school bus routing problem", Odysseus 2006, third international workshop on freight transportation and logistics, Altea, Spain. pp. 285-8, (2006)

22. Schittekat P, Sevaux M, S" orensen K "A mathematical formulation for a school bus routing problem", IEEE 2006 international conference on service systems and service management, Troyes, France, pp. 1552-7, (2006)

23. Riera-Ledesma J, Salazar-Gonza'lez JJ, "Solving school bus routing using the multiple vehicle traveling purchaser problem: a branch-and-cut approach", Computers \& Operations Research, pp. 391-404, (2012)

24. Bodin L, Berman L, "Routing and scheduling of school buses by computer", Transportation Science, pp. 113-129, 1979.

25. Dulac G, Ferland JA, Forgues PA, "School bus routes generator in urban surroundings", Computers \& Operations Research, pp. 199-213, (1980)

26. Desrosiers J, Ferland JA, Rousseau JM, Lapalme G, Chapleau L, "Transcol: a multi-period school bus routing and scheduling system", TIMS Studies in the Management Sciences, pp. 47-71, (1986)

27. Chapleau L, Ferland JA, Rousseau JM, "Clustering for routing in densely populated areas", European Journal of Operational Research, pp. 48-57, (1985)

28. Bowerman R, Hall B, Calamai P, "A multi-objective optimization approach to urban school bus routing: formulation and solution method", Transportation Research Part A, pp. 107-23, (1995)

29. Schittekat, P., Kinable, J., Sörensen, K., Sevaux, M., Spieksma, F., \& Springael, J, "A metaheuristic for the school bus routing problem with bus stop selection", European Journal of Operational Research, pp. 518-528, (2013)

30. J. Euchi and R. Mraihi, "The urban bus routing problem in the Tunisian case by the hybrid artificial ant colony algorithm," Swarm Evolutionary Computation, vol. 2, pp. 15-24, (2012)

31. J. Pacheco, R. Caballero, M. Laguna, and J. Molina, "Bi-Objective Bus Routing: An Application to School Buses in Rural Areas," Transportation Science, vol. 1655, pp. 1-15, (2012) 
32. B.-I. Kim, S. Kim, and J. Park, "A school bus scheduling problem," European Journal of Operational Research, vol. 218, no. 2, pp. 577-585, (2012)

33. J. Park, H. Tae, and B. I. Kim, "A post-improvement procedure for the mixed load school bus routing problem," European Journal of Operational Research, vol. 217, no. 1, pp. 204-213, (2012)

34. S. M. Song and T. Kim, "Customer-oriented school bus operations for childcare centers in Korea," Computers and Industrial Engineering, vol. 66, no. 1, pp. 116-124, (2013)

35. J. Kinable, F. C. R. Spieksma, and G. Vanden Berghe, "School bus routing-a column generation approach," International Transactions in Operational Research, vol. 21, no. 3, pp. 453-478, (2014)

36. M. Bogl, K. F. Doerner, and N. P. Sophie, "The School Bus Routing and Scheduling Problem with Transfers," Networks, vol. 47, no. 1, pp. 26-36, (2015)

37. X. Chen, Y. Kong, L. Dang, Y. Hou, and X. Ye, "Exact and Metaheuristic Approaches for a BiObjective School Bus Scheduling Problem," PLoS One, vol. 10, no. 7, (2015)

38. A. Anund and T. Dukic, "From user wishes to system architecture safety for children going to and from school by bus," IEEE 11th International Conference on ITS Telecommunications, ITST 2011, pp. 327-331, (2011)

39. K. Shaaban, A. Bekkali, E. Ben Hamida, and A. Kadri, "Smart Tracking System for School Buses Using Passive RFID Technology to Enhance Child Safety," Journal of Traffic and Logistics Engineering, vol. 1, no. 2, pp. 191-196, (2013)

40. J. Zambada, R. Quintero, R. Isijara, R. Galeana, and L. Santillan, "An IoT based scholar bus monitoring system," IEEE First International Smart Cities Conference, (2015)

41. J. Saranya and J. Selvakumar, "Implementation of children tracking system on android mobile terminals," IEEE International Conference on Communication and Signal Processing, ICCSP 2013 - Proc., pp. 961-965, (2013)

42. A. Al-lawati, S. Al-jahdhami, A. Al-belushi, D. Aladawi, M. Awadalla, and D. Al-abri, "RFID-based System for School Children Transportation Safety Enhancement," 8th IEEE GCC Conference and Exhibition, Muscat, Oman, (1-4 February, 2015)
43. P. Collins, Y. Al-Nakeeb, and M. Lyons, "Tracking the Commute Home From School Utilising GPS and Heart Rate Monitoring: Establishing the Contribution to Free-Living Physical Activity", Journal of Physical Activity \& Health, vol. 12, pp. 155-162, (2015)

44. A. Ito, Y. Kakuda, T. Ohta, and S. Inoue, "Safety Support System on School Routes Based on Grouping of Children in Mobile Ad Hoc Networks," IEEE Tenth International Symposium on Autonomous Decentralized Systems, pp. 533-538, (2011)

45. K. Kraschl-Hirschmann and M. Fellendorf, "Estimating energy consumption for routing algorithms," 2012 IEEE Intelligent Vehicles Symposium, Proceedings, pp. 258-263, (2012)

46. M. Richter and H. Kabza, "Strategic dynamic traffic routing algorithm for globally optimized urban traffic," IEEE Intelligent Vehicles Symposium, Proceedings, pp. 756-762, (2013)

47. A. Amini, R. M. Vaghefi, J. M. De Garza, and R. M. Buehrer, "Improving GPS-Based Vehicle Positioning for Intelligent Transportation Systems," Intelligent Vehicles Symposium Proceedings, 2014 IEEE, pp. 1023-1029, (2014)

48. S. Fiocchi, I. a. Markakis, P. Ravazzani, and T. Samaras, "SAR exposure from UHF RFID reader in adult, child, pregnant woman, and fetus anatomical models," Bio electromagnetics, vol. 34, no. April, pp. 443-452, (2013)

49. M. Redmayne and O. Johansson, "Radiofrequency exposure in young and old: different sensitivities in light of age-relevant natural differences," Rev. Environ. Health, vol. 30, no. 4, pp. 323-335, (2015)

50. H. Eren, S. Makinist, E. Akin, and A. Yilmaz, "Estimating driving behavior by a smartphone," 2012 IEEE Intelligent Vehicles Symposium, Proceedings, no. 254, pp. 234-239, (2012)

51. R. Araújo, Â. Igreja, R. De Castro, and R. E. Araújo, "Driving coach: A smartphone application to evaluate driving efficient patterns," IEEE Intelligent Vehicle Symposium, Proceedings, vol. 1, no. 1, pp. 1005-1010, (2012)

52. Amanda McElfresh, "Official: School bus tracking needs improvement", theadvertiser part of the USA today network, (Jan. 5 2016)

53. The associated press, "Official: Lafayette school bus tracking needs improvement", kansascity news, (Jan. 6 2016) 